NASA/TM-2002-211969

\title{
Ion Engine and Hall Thruster Development at the NASA Glenn Research Center
}

Matthew T. Domonkos, Michael J. Patterson, and Robert S. Jankovsky

Glenn Research Center, Cleveland, Ohio 
Since its founding, NASA has been dedicated to the advancement of aeronautics and space science. The NASA Scientific and Technical Information (STI) Program Office plays a key part in helping NASA maintain this important role.

The NASA STI Program Office is operated by Langley Research Center, the Lead Center for NASA's scientific and technical information. The NASA STI Program Office provides access to the NASA STI Database, the largest collection of aeronautical and space science STI in the world. The Program Office is also NASA's institutional mechanism for disseminating the results of its research and development activities. These results are published by NASA in the NASA STI Report Series, which includes the following report types:

- $\quad$ TECHNICAL PUBLICATION. Reports of completed research or a major significant phase of research that present the results of NASA programs and include extensive data or theoretical analysis. Includes compilations of significant scientific and technical data and information deemed to be of continuing reference value. NASA's counterpart of peerreviewed formal professional papers but has less stringent limitations on manuscript length and extent of graphic presentations.

- TECHNICAL MEMORANDUM. Scientific and technical findings that are preliminary or of specialized interest, e.g., quick release reports, working papers, and bibliographies that contain minimal annotation. Does not contain extensive analysis.

- CONTRACTOR REPORT. Scientific and technical findings by NASA-sponsored contractors and grantees.
- CONFERENCE PUBLICATION. Collected papers from scientific and technical conferences, symposia, seminars, or other meetings sponsored or cosponsored by NASA.

- SPECIAL PUBLICATION. Scientific, technical, or historical information from NASA programs, projects, and missions, often concerned with subjects having substantial public interest.

- TECHNICAL TRANSLATION. Englishlanguage translations of foreign scientific and technical material pertinent to NASA's mission.

Specialized services that complement the STI Program Office's diverse offerings include creating custom thesauri, building customized databases, organizing and publishing research results ... even providing videos.

For more information about the NASA STI Program Office, see the following:

- Access the NASA STI Program Home Page at http://www.sti.nasa.gov

- E-mail your question via the Internet to help@sti.nasa.gov

- Fax your question to the NASA Access Help Desk at 301-621-0134

- Telephone the NASA Access Help Desk at 301-621-0390

- Write to:

NASA Access Help Desk

NASA Center for AeroSpace Information 7121 Standard Drive

Hanover, MD 21076 
NASA/TM-2002-211969

IMECE-2002-34444

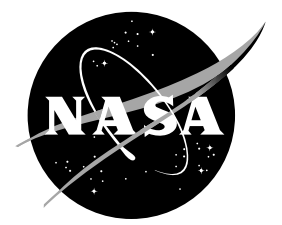

\section{Ion Engine and Hall Thruster Development at the NASA Glenn Research Center}

Matthew T. Domonkos, Michael J. Patterson, and Robert S. Jankovsky

Glenn Research Center, Cleveland, Ohio

Prepared for the

2002 International Mechanical Engineering Congress

sponsored by the American Society of Mechanical Engineers

New Orleans, Louisiana, November 17-22, 2002

National Aeronautics and

Space Administration

Glenn Research Center 


\section{Acknowledgments}

The authors acknowledge the intellectual contributions of Vince Rawlin, James Sovey, Robert Roman, George Soulas, John Foster, David Manzella, Luis Pinero, Glen Bowers, George Williams, David Jacobson, Scott Kovaleski,

Richard Hofer, Peter Peterson, and Christian Carpenter. The authors appreciate the excellent technical support provided by Michael Pastel, Patrick Barber, Richard Polak, Chris Kandrach, James Kelly, Hardy Hartman, Restituto Palad, Joseph Dick, Ivan Ocasio, Kevin Blake, Howard Eakin, Eli Green, George Jacynycz, Terry Jansen, Bob Braun, and John Johnson. The programs described in this paper are supported by the Office of Space Science, the Energetics Program, the Space Solar Power Program, and the In-Space Propulsion Program.

Available from

NASA Center for Aerospace Information 7121 Standard Drive

Hanover, MD 21076
National Technical Information Service 5285 Port Royal Road Springfield, VA 22100 
IMECE-2002-39444

\title{
ION ENGINE AND HALL THRUSTER DEVELOPMENT AT THE NASA GLENN RESEARCH CENTER
}

\author{
Matthew T. Domonkos \\ National Aeronautics and Space Administration \\ Glenn Research Center \\ Cleveland, Ohio 44135 \\ Matthew.T.Domonkos@grc.nasa.gov
}

\author{
Michael J. Patterson \\ National Aeronautics and Space Administration \\ Glenn Research Center \\ Cleveland, Ohio 44135 \\ Michael.J.Patterson@grc.nasa.gov
}

\author{
Robert S. Jankovsky \\ National Aeronautics and Space Administration \\ Glenn Research Center \\ Cleveland, Ohio 44135 \\ Robert.S.Jankovsky@grc.nasa.gov
}

\begin{abstract}
NASA's Glenn Research Center has been selected to lead development of NASA's Evolutionary Xenon Thruster (NEXT) system. The central feature of the NEXT system is an electric propulsion thruster (EPT) that inherits the knowledge gained through the NSTAR thruster that successfully propelled Deep Space 1 to asteroid Braille and comet Borrelly, while significantly increasing the thruster power level and making improvements in performance parameters associated with NSTAR. The EPT concept under development has a $40 \mathrm{~cm}$ beam diameter, twice the effective area of the Deep-Space 1 thruster, while maintaining a relatively-small volume. It incorporates mechanical features and operating conditions to maximize the design heritage established by the flight NSTAR $30 \mathrm{~cm}$ engine, while incorporating new technology where warranted to extend the power and throughput capability.

The NASA Hall thruster program currently supports a number of tasks related to high power thruster development for a number of customers including the Energetics Program (formerly called the Space-based Program), the Space Solar Power Program, and the In-space Propulsion Program. In program year 2002, two tasks were central to the NASA Hall thruster program: 1.) the development of a laboratory Hall thruster capable of providing high thrust at high power; 2.) investigations into operation of Hall thrusters at high specific impulse. In addition to these two primary thruster development activities, there are a number of other on-going activities supported by the NASA Hall thruster program. These additional activities are related to issues such as thruster lifetime and spacecraft integration.
\end{abstract}

\section{INTRODUCTION}

The success of the NASA Solar Electric Propulsion Technology Applications Readiness (NSTAR) program ion propulsion system on the Deep-Space 1 spacecraft[1] has secured the future for this propulsion technology for other NASA missions. The successful demonstration of the NSTAR ion thruster has provided future mission planners with an offthe-shelf $2.5 \mathrm{~kW}$ ion thruster. The $2.5 \mathrm{~kW}$ ion propulsion system on Deep-Space 1 performed flawlessly in space operating over 16,000 hours and processing in excess of $70 \mathrm{~kg}$ of xenon propellant.

While the NSTAR thruster is appropriate in terms of power level and lifetime for Discovery Class as well as other, smaller NASA missions, its application to large flag-ship type missions such as outer planet explorers and sample return missions is limited due its lack of power and total impulse capability. Several missions under consideration for the Exploration of the Solar System, part of NASA's Space Science Enterprise, have identified a higher power, higher throughput capability, $5 / 10-\mathrm{kW}$ ion propulsion system as an enabling technology. These missions include the Europa Lander, the Saturn Ring Observer, the Neptune Orbiter, and the Venus Surface Sample Return $[2,3]$.

A NASA Glenn Research Center (GRC)-led team has recently been awarded a NASA Office of Space Science research project to develop the next generation of ion propulsion system. The successful proposal, for NASA's Evolutionary Xenon Thruster (NEXT), was developed by a team composed of GRC, the Jet Propulsion Laboratory (JPL), General Dynamics Space Propulsion Systems (GD-SPS), 
Boeing Electron Dynamic Devices (BEDD), Applied Physics Laboratory, University of Michigan, and Colorado State University.

Additionally, NASA's ion propulsion program is also funded under the Energetics Program to develop fundamental technology for ion engine applications. Under this program, microwave discharge chambers and cathodes are being investigated as possible replacements for the hollow cathodes in ion engines operating at tens of kilowatts and requiring life to much more than 10,000 hours. Development of a low power (several hundred Watt) ion thruster to engineering model maturity is also being pursued. Propellantless cathode technology development, real-time, laser-based erosion diagnostics, discharge chamber modeling, and measurement of low-energy sputter yields are also funded under the Energetics Program.

The NASA Hall thruster program at the Glenn Research Center currently supports a number of tasks related to high power thruster development for a number of customers including the Energetics Program, the Space Solar Power Program, and the In-space Propulsion Program. High power ( $>>10-\mathrm{kW}$ ) thruster development is being emphasized because recent mission analyses have shown a need for higher power electric propulsion systems for both Earth orbital and deep space applications. However, these different applications require propulsion systems with different optimal characteristics. Earth orbital applications such as space tugs, spacecraft orbit insertion, etc. benefit from high thrust electric propulsion systems for timely space transfers. In contrast, deep space missions typically have large delta $\mathrm{V}$ requirements necessitating high specific impulse $[4,5,6]$. For recently considered power rich spacecraft architectures, both high power and high specific impulse propulsion systems are required [7]. The application of Hall thrusters to either mission type requires substantial technology advancements from state-of-the-art (SOA) thrusters.

In program year (PY) 2002, two tasks were central to the NASA Hall thruster program: 1.) the development of a laboratory Hall thruster capable of providing high thrust at high power; 2.) investigations into operation of Hall thrusters at high specific impulse.

Specifically the first task resulted in investigations of the issues associated with scaling a single thruster to power levels substantially in excess of the SOA. A $50-\mathrm{kW}$ class Hall thruster was designed, built and operated over the range of 9 to $72 \mathrm{~kW}$. The second task has focused on investigating factors critical to high specific impulse operation. This year the investigation has considered the role of magnetic field topography on high voltage operation.

In addition to these two primary thruster development activities, there are a number of other on-going activities supported by the NASA Hall thruster program. These additional activities are related to issues such as thruster lifetime, high-power power processor architecture and spacecraft integration. Thruster lifetime issues were investigated by considering the impact of Hall thruster operation at high voltage on thruster lifetime. Breadboard power system tests were conducted with a single power converter that may be suited for high-power power processing unit (PPU) architecture studies. Impedance measurements of a Hall thruster were made in an effort to develop an electrical model of a Hall thruster to enable optimum and cost effective PPU design. Finally, a new effort to consider the dynamic electrical behavior of Hall thruster discharges was initiated. This was deemed necessary due to the importance of electromagnetic interference (EMI) concerns as a spacecraft integration issue. A detailed overview of each of these activities and their current status are included in this report.

\section{NASA'S EVOLUTIONARY XENON THRUSTER (NEXT)}

NEXT, which is part of the Next Generation Ion Project managed by NASA's Marshall Space Flight Center, Huntsville, Al., will consist of two phases. The first is a demonstration of initial components within one year. The second phase, which NASA may exercise as an option, will last approximately 2.5 years and will advance the system's maturity to NASA Technology Readiness Level (TRL) 5 (component and/or breadboard validation in relevant environment), with significant progress towards TRL 6 (prototype demonstration in relevant environment), thereby achieving a stage of development where the technology can be provided to NASA users to incorporate into planned missions.

The NEXT system will consist of the following:

- A 40-cm diameter electric propulsion thruster (EPT) with a specific impulse of at least 4000 seconds, a specific mass $>3.6 \mathrm{~kg} / \mathrm{kW}$, efficiencies greater than the NSTAR thruster at all power levels, and a propellant throughput capability required to execute the design reference missions;

- a lightweight, modular power processing unit (PPU) with an efficiency and a specific power equal-to or better-than the NSTAR PPU;

- a highly flexible advanced xenon feed system (AXFS) which uses proportional valves and thermal throttles to significantly reduce mass and volume relative to the NSTAR feed system; and

- a simple, lightweight EPT gimbal.

Validation of NEXT will dramatically advance state-of-the-art ion propulsion technology, with significant gains in EPT capability, as enumerated in Table 1.

Table 1 - EPT Attribute Comparison

\begin{tabular}{|l|c|c|}
\hline \multicolumn{1}{|c|}{ Engine Attribute } & NSTAR & NEXT \\
\hline Max. Input Power, kW & 2.3 & Up to 8 \\
\hline Throttle Range & $4: 1$ & Up to $8: 1$ \\
\hline Max. Specific Impulse, $\mathrm{S}$ & 3,170 & 74,050 \\
\hline Efficiency @ Full Power & $62 \%$ & $768 \%$ \\
\hline Propellant Throughput, kg & 83 design, 140 demo & $>300$ \\
\hline Specific Mass, kg/kW & 3.6 & $>3.6$ \\
\hline
\end{tabular}

The NEXT thruster approach leverages the investments made at GRC in fiscal year 2001 for the development of a next generation engine [8,9]. During this time, design analyses were performed, throttling tables were defined, two engine concepts were developed, and laboratory model (LM) engines were fabricated [9]. The design of the discharge chamber magnetic circuit, magnet retention scheme, and flake-containment approach was completed, and multiple 40-cm diameter ion optics and discharge cathode assemblies were fabricated. 
Preliminary performance characterizations of a $40-\mathrm{cm} \mathrm{LM}$ engine were conducted for input power levels ranging from about $1.1 \mathrm{~kW}$ to $7.3 \mathrm{~kW}$ [9]. The efficiency at $7.3 \mathrm{~kW}$ was approximately $68 \%$ at 3,620 seconds specific impulse. Ion optics performance (purveyance and electron backstreaming; beam divergence and beam current density profiles) was documented, as were temperatures of critical components, including the discharge cathode and magnets. The 40-cm ion optics performance was comparable to the $30-\mathrm{cm}$ NSTAR flight ion optics [10]. Test data show that discharge cathode and magnet temperatures for the $40-\mathrm{cm}$ engine are within design limits and provide significant design margin up to at least $10 \mathrm{~kW}$.

\section{Thruster Design}

For NEXT, an NSTAR-derivative engine with $40 \mathrm{~cm}$ beam diameter was selected $[11,12,13,14]$. An engine of this size has twice the beam area of the NSTAR $30 \mathrm{~cm}(28 \mathrm{~cm}$ beam diameter) thruster. Doubling the beam area allows operation at significantly higher power while maintaining low voltages and current densities. Thus, potential complications associated with high-voltage electrode operations are avoided. At an input power of $4.7 \mathrm{~kW}$, the engine would be operating at approximately the same operating voltages and beam current density as the $2.3 \mathrm{~kW}$ NSTAR thruster, and hence would be expected to yield the same operating lifetime, but producing twice the thrust.

The NSTAR thruster has demonstrated $>195 \mathrm{~kg}$ propellant throughput in ground testing, which is substantially higher than the original design goal of $83 \mathrm{~kg}$. A greater than 2 times increase in throughput capability for the $40-\mathrm{cm}$ engine is anticipated (based on a 2 times increase in beam area, an improved flatness parameter, and an associated reduction in local charge exchange production [8]) which is sufficient to meet mission requirements. The engine capability is expected to reach $>300-\mathrm{kg}$ by virtue of an advanced, molybdenum ion optics design that includes an accelerator electrode that is thicker than that of NSTAR [10]. This is beyond the "singleengine-out' requirement for proposed Neptune and Saturn missions.

The NEXT 40-cm engine incorporates design improvements beyond NSTAR. These improvements include:

- A discharge chamber with improved beam flatness and reduced discharge losses

- High-temperature stabilized rare-Earth magnets

- A compact propellant isolator

- Advanced ion optics design for longer life

The mechanical integrity and design maturity of the $40-\mathrm{cm}$ EM engine at the completion of the project first phase is expected to be superior to that of the engineering model of the NSTAR thruster (also manufactured by GRC) because it is being designed for the anticipated vibration environment.

Stainless steel is used in the construction of the discharge chambers for the $40 \mathrm{~cm} \mathrm{LM}$ and EM engine designs fabricated at NASA GRC. Both $40 \mathrm{~cm}$ engine designs use ring-cusp magnetic circuits, with high-field strength permanent magnets for plasma containment [15]. A flake-retention scheme is employed in the discharge chamber, which also acts as a magnet retainer. The material, preparation, and installation processes employed for the flake-retention system are identical to those implemented on the NSTAR $30 \mathrm{~cm}$ thruster. Both LM and EM $40 \mathrm{~cm}$ engines also incorporate a reverse-feed propellant injection process for the main plenum.

The discharge cathode assembly for the $40 \mathrm{~cm}$ engine is scaled from the NSTAR $6.4 \mathrm{~mm}$ diameter hollow cathode to accommodate the estimated emission current range, and uses similar design and manufacturing processes. The neutralizer is an enclosed-keeper hollow cathode assembly. Internal dimensions are adjusted to accommodate the higher emission current requirements for the $40 \mathrm{~cm}$ engine, and do so at reduced ratios of propellant flow rate-to-emission current, relative to the NSTAR neutralizer cathode.

Two design approaches are being pursued for the $40 \mathrm{~cm}$ ion optics. These include: NSTAR-type electrodes of increased beam diameter, and thicker accelerator-electrode geometry. Both are two-grid designs constructed of molybdenum. The electrode mounting system is scaled from the NSTAR design and also uses the same materials as implemented in the $30 \mathrm{~cm}$ thruster. Figure 1 shows an isometric perspective of the $40 \mathrm{~cm}$ $\mathrm{EM}$ version of the engine.

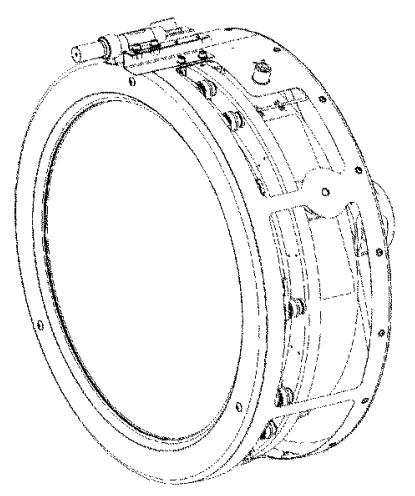

Figure 1 - Isometric Drawing of the NEXT 40-cm EM Ion Engine.

\section{Thruster Manufacturing and Performance Evaluation}

NEXT's $40-\mathrm{cm}$ engine will leverage the manufacturing processes of the GRC NSTAR ion thruster. Heritage from NSTAR includes critical processes used in subassemblies, such as the spun-form chamber components; cathode heaters and components; ion optics; propellant isolators; flake-containment mesh; and electrical wiring. The continuity between NSTAR and NEXT is intended to minimize the set of unknowns associated with a new mechanical design and maximizes the value of previous investments in ion engine technology.

Performance assessments will evaluate engine operation over its design input power throttling and specific impulse ranges. They will also provide information for service life and thermal modeling. Performance assessments will be conducted on all EM and PM engines in Phases 1 and 2. These will include component (i.e. discharge chamber, neutralizer, and ion optics performance) and engine performance.

The following beam parameters will also be documented:

- Beam flatness for grid service life modeling

- Beam divergence to determine thrust losses 
- Beam plasma potentials for spacecraft interactions modeling

- Doubly-to-singly-charged ion current measurements to determine thrust losses

- Thrust vector stability

The selection criterion for the facilities proposed for engine performance assessments is to establish the highest-fidelity simulation required for each specific test to yield transportable results. For wear test evaluations of the engine, GRC's VF5 and VF6, the highest pumping speed and largest electric propulsion vacuum facilities in the country, will be used.

\section{Thruster Life Testing and Assessment}

The NEXT 40-cm engine life capability will be validated through a combination of high-power wear tests and modeling. Previous ion engine wear tests revealed unanticipated wear mechanisms [16,17,18]. Experimental evaluations form the backbone of the NEXT validation process and are essential to life demonstration. The wear tests, in situ diagnostics, and realtime diagnostics will yield reliable life data with minimal time expenditure and cost. The lifetime modeling efforts will be implemented to reduce the experimental workload and enhance the confidence in the design life. A list of key life-limiting issues is given in Table 2, along with the techniques to be employed in the life assessment.

\section{Table 2 - EPT Life-Limiting Issues}

\begin{tabular}{|c|c|c|}
\hline Component & $\begin{array}{l}\text { Life-Limiting } \\
\text { Phenomenon }\end{array}$ & Technique \\
\hline $\begin{array}{l}\text { Discharge } \\
\text { and } \\
\text { Neutralizer } \\
\text { Cathodes }\end{array}$ & $\begin{array}{l}\text { - Depletion of low- } \\
\text { work function } \\
\text { material } \\
\text { - Keeper and cathode } \\
\text { erosion leads to } \\
\text { structural failure } \\
\text { - Keeper shorts to the } \\
\text { cathode }\end{array}$ & $\begin{array}{l}\text { - Wear tests } \\
\text { - Component level tests } \\
\text { - } \text { Real-time diagnostics } \\
\text { - Plasma model } \\
\text { - Insert Chemistry } \\
\text { model } \\
\text { - Probabilistic Failure } \\
\text { Analysis (PFA) } \\
\end{array}$ \\
\hline Accel Grid & $\begin{array}{l}\text { - Aperture enlargement } \\
\text { leads to electron } \\
\text { backstreaming } \\
\text { - Structural failure due } \\
\text { to erosion } \\
\text { - Accel and screen grid } \\
\text { short together }\end{array}$ & $\begin{array}{l}\text { - Wear Tests } \\
\text { - Real-time diagnostics } \\
\text { - In situ diagnostics } \\
\text { - Plasma model } \\
\text { - PFA }\end{array}$ \\
\hline $\begin{array}{l}\text { Screen } \\
\text { Grid }\end{array}$ & $\begin{array}{l}\text { Removal of web } \\
\text { leads to: direct } \\
\text { impingement on the } \\
\text { accel grid, and } \\
\text { structural failure }\end{array}$ & $\begin{array}{l}\text { - Wear Tests } \\
\text { - Real-time diagnostics } \\
\text { - Plasma model } \\
\text { - PFA }\end{array}$ \\
\hline $\begin{array}{l}\text { Propellant } \\
\text { Isolators }\end{array}$ & $\begin{array}{l}\text { Increasing leakage } \\
\text { current with time }\end{array}$ & $\begin{array}{l}\text { - Wear tests } \\
\text { - Component level tests }\end{array}$ \\
\hline
\end{tabular}

\section{Thruster Development Status}

Fabrication of LM $40 \mathrm{~cm}$ engines has been completed, and detailed performance characterizations are on-going at NASA GRC. An EM 40-cm engine design (see Figure 1) based on the most promising LM concept has been assembled and is also under test. The design of several components for the EM engine-including the spun-formed, partial-conic discharge chamber, hollow-cathodes, and ion optical system-are derived from NSTAR engine technology.

Table 3 provides performance data for the LM version of the $40 \mathrm{~cm}$ engine operating on xenon propellant for a power range from about 1.1 to $6.9 \mathrm{~kW}$, where $\mathrm{V}_{\mathrm{bps}}$ is the beam power supply voltage. As indicated, the specific impulse and efficiency varies from about 4060 seconds and 0.69 at $6.9 \mathrm{~kW}$, down to about 2300 seconds and 0.51 at $1.1 \mathrm{~kW}$.

\section{Table 3 - EPT Performance}

\begin{tabular}{|c|c|c|c|c|}
\hline $\mathrm{V}, \mathrm{V}_{\mathrm{bps}}$ & $\mathrm{F}, \mathrm{mN}$ & $\mathrm{I}_{\mathrm{sp}}, \mathrm{sec}$ & $\mathrm{P}_{\mathrm{in}}, \mathrm{kW}$ & Eff. \\
\hline \multicolumn{5}{|c|}{$5.92 \mathrm{mg} / \mathrm{sec}$} \\
\hline 1800 & 238 & 4060 & 6.90 & 0.69 \\
\hline 1570 & 222 & 3750 & 6.06 & 0.67 \\
\hline 1400 & 211 & 3570 & 5.50 & 0.67 \\
\hline 1180 & 192 & 3255 & 4.70 & 0.65 \\
\hline \multicolumn{5}{|c|}{$4.65 \mathrm{mg} / \mathrm{sec}$} \\
\hline 1800 & 182 & 3950 & 5.29 & 0.67 \\
\hline 1570 & 170 & 3690 & 4.67 & 0.66 \\
\hline 1400 & 160 & 3480 & 4.21 & 0.65 \\
\hline 1180 & 148 & 3200 & 3.64 & 0.64 \\
\hline 1020 & 137 & 2970 & 3.21 & 0.62 \\
\hline \multicolumn{5}{|c|}{$3.43 \mathrm{mg} / \mathrm{sec}$} \\
\hline 1800 & 135 & 3970 & 3.98 & 0.66 \\
\hline 1570 & 126 & 3700 & 3.51 & 0.65 \\
\hline 1400 & 119 & 3490 & 3.17 & 0.64 \\
\hline 1180 & 109 & 3200 & 2.74 & 0.63 \\
\hline 1020 & 102 & 2980 & 2.43 & 0.61 \\
\hline \multicolumn{5}{|c|}{$2.17 \mathrm{mg} / \mathrm{sec}$} \\
\hline 1800 & 81.4 & 3770 & 2.44 & 0.62 \\
\hline 1570 & 75.7 & 3510 & 2.15 & 0.60 \\
\hline 1400 & 71.5 & 3310 & 1.95 & 0.60 \\
\hline 1180 & 65.7 & 3040 & 1.69 & 0.59 \\
\hline 680 & 49.6 & 2300 & 1.11 & 0.51 \\
\hline
\end{tabular}

\section{ION ENGINE DEVELOPMENT ACTIVITIES}

\section{High-Power Engine and Component Technologies}

The long-range goal of this activity is to develop and demonstrate ion engine operation at $30 \mathrm{~kW}$ input power levels and above, at specific impulse levels of interest to support human exploration of the solar system. A near term objective is the demonstration of ion engine operation in the range of 10 to $30 \mathrm{~kW}$, at 4000 seconds specific impulse.

As part of this activity, development work in high-current hollow cathodes was initiated at NASA GRC. This included the design and fabrication of high-current hollow cathode assemblies $[19,20]$. A laboratory model 100-A class cathode operated stably over a range of emission currents from about $14 \mathrm{~A}$ to $100 \mathrm{~A}$ on xenon propellant, although thermal-redesign is required to yield adequate life time at $>50$ Amperes emission current.

\section{NSTAR Derivative Technologies}

The activities under this element are focused on development of component technologies for NSTAR-derivative high-throughput ion engines.

\section{lon Optics}

The primary objective of this effort is to develop and validate ion optics designs which yield a $>2 \mathrm{x}$ increase in life 
over that demonstrated with the Deep Space 1 ion engine optics technology. This includes efforts in both metallic (molybdenum and titanium) as well as carbon-based (carbon-carbon, and pyrolytic graphite) ion optics designs.

In the metallic optics work, evaluations of both thickaccelerator-grid (TAG) electrode molybdenum designs, and titanium designs are underway. TAG molybdenum ion optics of $30 \mathrm{~cm}$ diameter have been manufactured in-house and characterized over, and beyond, the Deep Space 1 power throttling envelope [21]. The TAG ion optics utilize a 50\% thicker accelerator grid (relative to the Deep Space 1 design) in an attempt to double the optics service life. The TAG design has demonstrated comparable perveance to that obtained with flight ion optics for the NSTAR Deep Space 1 engine [21].

Titanium ion optics of $30 \mathrm{~cm}$ diameter have also been manufactured and performance characterized [22]. The potential advantages of titanium, over molybdenum, include a lower volumetric sputter erosion rate, reduced cost of manufacturing, and reduced optics assembly mass. The performance of these optics compare favorably to those of the NSTAR design as well. Additional work to be performed includes detailed evaluations of the transient electrode gap change of titanium optics under thermal load.

Carbon-based ion optics are also under design and manufacturing, with activities including fabrication of carbon/carbon composite grids using multiple vendors with alternate processes, and fabrication of pyrolytic graphite grids of $8 \mathrm{~cm}$ (Figure 2) and $30 \mathrm{~cm}$ diameter from a commercial supplier [23]. Graphite carbon has a very low sputter yield and coefficient of thermal expansion; the latter property is nearly zero in some situations. This is important in order to maintain precise geometric alignment between screen and accelerator aperture holes. High performance ion thrusters typically have large grid span-to-gap ratios which are vulnerable to thermal distortion. The high geometric stability of carbon materials may permit larger diameter thruster designs while still maintaining high beam density. Alternately, it may be possible to significantly increase the beam density of low power ion thrusters, improving applications on small spacecraft.

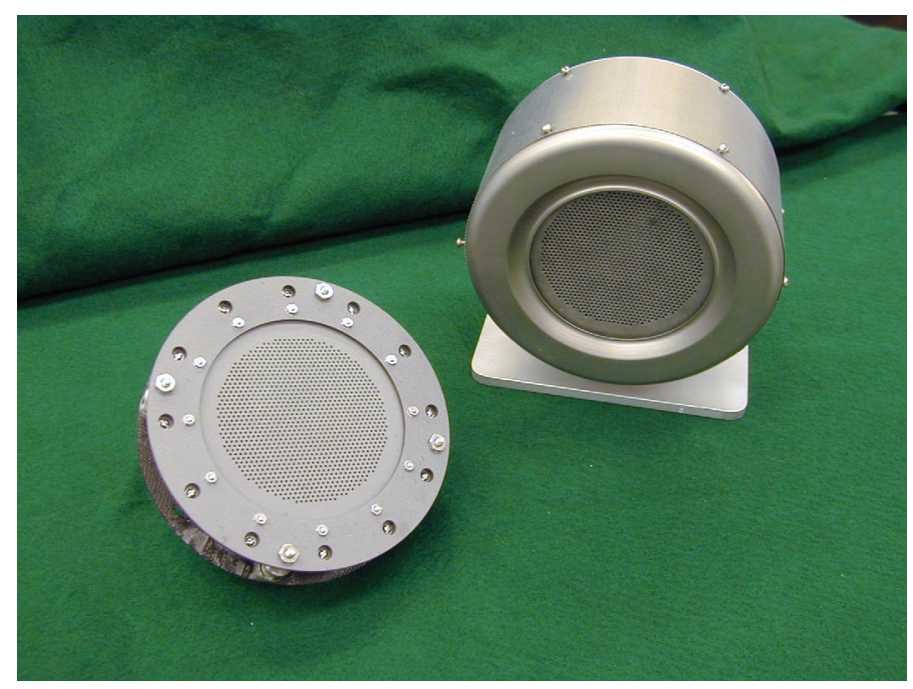

Figure 2 - 8-cm Diameter Pyrolytic Graphite Ion Optics (shown with 8-cm engine).

\section{Cathode Lifetime}

The requirements on hollow cathode life are growing more stringent with the increasing use of electric propulsion technology and demand for greater total impulse capability. The life limiting mechanism that determines the entitlement lifetime of a barium impregnated thermionic emission cathode is the evolution and transport of barium away from the emitter surface. In concert with a robust hardware development effort at NASA GRC [19,24], a model is being developed to study the process of barium transport and loss from the emitter insert in hollow cathodes [25].

The coupled thermochemistry/diffusion model has been developed for xenon hollow cathode operation and it shows good qualitative agreement with observable phenomena in hollow cathodes. The model has been used initially to examine the evolution and loss of $\mathrm{Ba}$ from the insert impregnate. Model results have also been compared to qualitative experimental evidence of chemical processes within the cathode insert.

\section{Flake Retention}

Grit-blasted wire mesh on stainless steel backing is commonly used in ion engine discharge chambers to ensure adherence of sputtered coatings. Spalled coatings or flakes pose some risk in shorting the high-voltage ion optics. If spalling does occur, the fine wire mesh ensures the spalled material will have sufficiently small dimensions so electrode gaps cannot be bridged. A 8,200 hour ground test of a $2.3 \mathrm{~kW}$ ion engine had no problems that could be attributed to spalled flakes [1]. This test had a xenon throughput of $88 \mathrm{~kg}$. Post-test analyses indicated the coatings and flakes were primarily molybdenum and were in the $2 \mu \mathrm{m}$ to $12 \mu \mathrm{m}$ thickness range. The Deep Space One ion engine has operated in zero-g conditions for over 16,000 hours, and no problems have been encountered due to spalling of the chamber coatings.

\section{Sub-Kilowatt Ion Propulsion}

The goal of this activity is to develop lightweight $(<3.0 \mathrm{~kg}$ combined mass), sub-kilowatt thruster and power processor technology. Performance goals include $50 \%$ efficiency at $0.25 \mathrm{~kW}$, representing a $2 \mathrm{x}$ increase over state-of-the-art.

The sub-kilowatt ion propulsion activity includes both an in-house hardware development element for the thruster and power processor, as well as a contracted system element. At NASA GRC, the fabrication and performance assessment of a small ( $0.25 \mathrm{~kW}$ class) laboratory model thruster with an $8 \mathrm{~cm}$ beam diameter has been completed [26,27,28]. Also at NASA GRC, first- and second-generation breadboard power processors have been fabricated and successfully integrated with the $8 \mathrm{~cm}$ thruster [29].

\section{Selected Fundamentals}

\section{Low-Energy Sputtering}

The objective of this activity is to develop a fundamental understanding of low energy sputtering processes, and to measure low energy sputtering yields of materials relevant to ion thrusters. This activity is being conducted jointly with Tuskegee University. A long range goal is to quantify the sputter yields of relevant refractory metals under ion bombardment, down to the threshold energies. A near-term 
goal is the quantification of the sputter yields of Ta, Ti, and Mo under Xe ion bombardment down to $100 \mathrm{eV}$.

To date, low energy $(<500 \mathrm{eV})$ xenon ion sputtering yields were measured of molybdenum and tantalum targets [30]. The sputtering was carried out in an ultra high vacuum chamber at NASA GRC. The targets were bombarded with a xenon ion beam generated by an ion gun capable of producing a beam current of approximately $1 \mu \mathrm{A}$. The sputtered atoms were captured on a semi-cylindrical aluminum collector strip, which was subsequently removed from the vacuum chamber and analyzed with a Rutherford Backscattering Spectrometer. The sputter yield was then obtained from the atomic density and thickness of the sputtered film.

\section{Cathode High Energy Ion Formation}

The production of energetic ions in a hollow cathode discharge is well documented [31,32,33,34]. These energetic ions have been detected at energies well in excess of the discharge voltage. Energetic ions are capable of eroding not only ion thruster cathode and keeper electrodes, but also discharge chamber surfaces such as the screen grid. Cathode production of energetic ions may be a thruster life-limiter particularly for long duration missions. The mechanism behind the production of these energetic ions remains unresolved [34]. Proposed mechanisms include multiply-charged ion processes, potential hills, charge-transfer effects, and z-pinch acceleration $[34,35]$. Though the theories explain the generation of energetic ions given the presence of certain mechanisms, compelling experimental evidence to support any of the theories remains elusive.

In order to address and better understand this issue, an experimental investigation of the formation of high energy ions in high-current hollow cathodes has been initiated at NASA GRC. The goal of this investigation is to characterize the energy distribution and estimate the magnitude of the energetic component of the emitted ions generated by a high current hollow cathode.

\section{Propellantless Cathode Technology}

The goal of this activity is to develop a propellantless cathode technology appropriate for electric propulsion applications. Low-power electric thrusters, spacecraft plasma contactors, and electrodynamic tether systems need electron emitters that require very low gas flow rates or zero gas flow to perform their functions. In order to ensure that very low-power colloid thrusters, Field Emission Electric Propulsion devices, ion engines, Hall thrusters, and gridded vacuum arc thrusters are reasonably attractive systems, a propellantless neutralizer cathode is highly desirable. NASA GRC is currently investigating the suitability of field emitter array and ferroelectric emission cathode technologies for electric propulsion thrusters.

\section{HALL THRUSTER DEVELOPMENT ACTIVITIES}

\section{High Power-High Thrust Performance}

The NASA Glenn Research Center Hall thruster program developed the laboratory model NASA-457M thruster (Figure 3). The thruster was designed and fabricated to nominally operate at $50 \mathrm{~kW}$ and $100 \mathrm{~A}$. The initial test program focused on establishing the operational characteristics and performance of the thruster at conservative power densities to identify any potential design deficiencies and to evaluate the viability of the scaling relationships used to design the thruster. Subsequent tests investigated thruster performance over an extended range of operating conditions. The results, as can be seen in Figure 4, demonstrated operation up to $72 \mathrm{~kW}$ and $3 \mathrm{~N}$ of thrust. At the design point of $500 \mathrm{~V}, 100$ A discharge specific impulse and efficiency were 2747 seconds and 63\%, respectively. Total specific impulse and efficiency with a non-optimized cathode were 2528 seconds and $56 \%$, also at $500 \mathrm{~V}, 100 \mathrm{~A}$. Thruster operation was stable over all conditions; the maximum power demonstrated thus far being limited only by available power supplies. Manzella, et al. has a complete description of the thruster and test results [36].

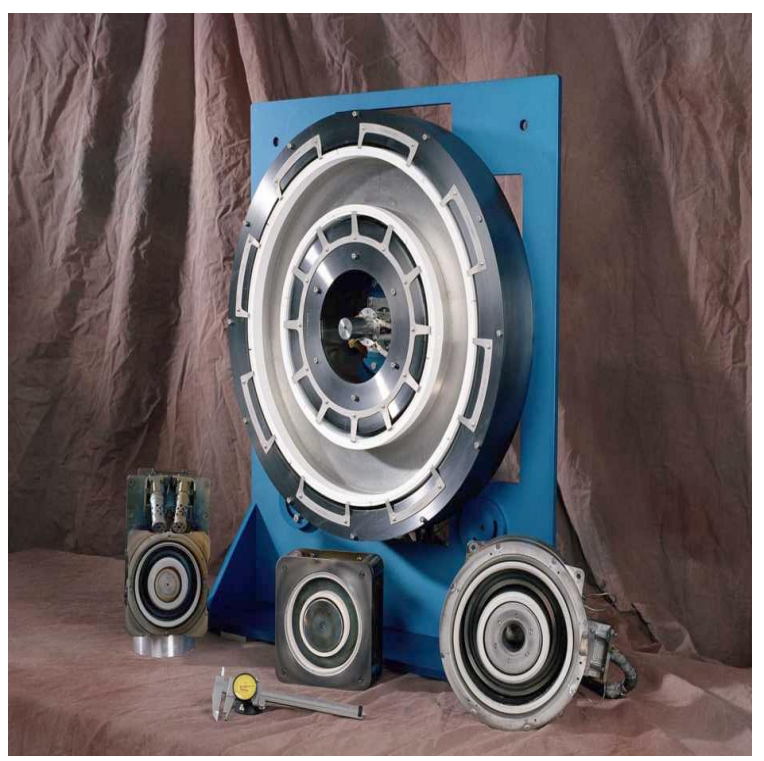

Figure 3 - NASA-457M (large thruster in the center), NASA-120M (small thruster in center), SPT-100 (left), T-160 (right).

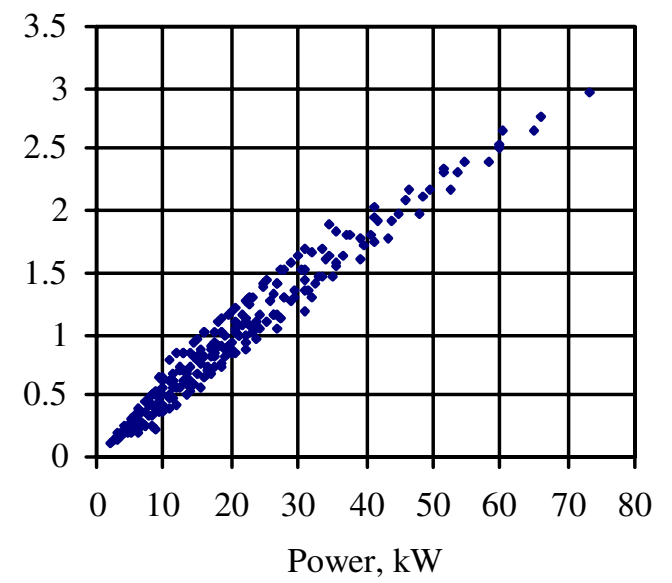

Figure 4 - Demonstrated Thrust (in Newtons) and Power Range of the NASA-457M Hall Thruster. 
Future efforts will focus on the effect of an auxiliary magnetic trim coil incorporated in the NASA-457M. Other NASA GRC funded efforts have recently shown how similar trim coils can enable efficient operation over a wide range of operating conditions [37,38].

Previous tests on smaller thrusters at NASA GRC have shown maximum discharge efficiencies at discharge voltages of 500 to $800 \mathrm{~V}$ depending on the flow rate $[39,40]$. Operation up to $1000 \mathrm{~V}$ and $100 \mathrm{~kW}$ will be investigated in order to establish maximums with regard to efficiency and specific impulse for the NASA-457M. These results will be incorporated into the findings from the high specific impulse work to be described subsequently.

\section{0 kW Hall Thruster Development}

The $50-\mathrm{kW}$ Hall thruster program is sponsored by the InSpace Program and is developing a $50 \mathrm{~kW}$-class Hall propulsion system through contract with industry. In February 2001, NASA released a request for offer (RFO) for the design and development of a $50 \mathrm{~kW}$ Hall thruster that could minimally provide $2.5 \mathrm{~N}$ of thrust at $50 \mathrm{~kW}$ using xenon as a propellant with a target thruster efficiency of at least $60 \%$.

Proposals were received, evaluated and Phase I design awards were made to General Dynamics and Busek Co. Due to funding limitations, only the General Dynamics Phase II fabrication option was exercised. General Dynamics offered two concepts including an SPT-type device and a SPT/TAL hybrid device. These proposed devices have been designed with an aggressive power density to enhance performance and reduce thruster mass. Typical Hall thruster power densities are nominally $55 \mathrm{~W} / \mathrm{cm}^{2}$ whereas the thrusters being considered will have a nominal power density of $110 \mathrm{~W} / \mathrm{cm}^{2}$.

In PY2002, funding constraints limited the scope of this effort to the fabrication of these devices. In PY2003, the functionality and performance of both thrusters will be evaluated. The thermal design will be verified and feasibility of the elevated power density assessed.

\section{High Specific Impulse Performance}

The Hall thruster program at NASA GRC has in recent years awarded several contracts to extend the operational envelope of Hall thrusters from the current SOA. These efforts have included investigations of operating thrusters at specific impulses $\left(\mathrm{I}_{\mathrm{sp}}\right)$ as low as 1000 seconds [37] and as high as 4100 seconds $[39,40,41]$.

Extending the operational envelope of Hall thrusters will benefit the two most prevalent trends in the community today, multi-mode and high power thrusters. For multi-mode thrusters, developing an understanding of the processes involved has the potential to lead to Hall thrusters that operate at $I_{\text {sp }}$ 's and efficiencies comparable to ion thrusters while offering the benefits of operating the same thruster in high thrust mode at reduced $I_{s p}(\sim 1000$ seconds). For high power thrusters, developing the design knowledge to extend the efficient operating range could be vitally important in controlling waste heat. A $50 \mathrm{~kW}$ Hall thruster utilizing standard design philosophies will most likely be about $60 \%$ efficient, which translates to as much as to $20 \mathrm{~kW}$ of waste heat that must be radiated or conducted away from the thruster. Clearly, the ability to increase the efficiency of a high power Hall thruster beyond the SOA would be beneficial to spacecraft integration issues.

In the high $\mathrm{I}_{\mathrm{sp}}$ regime, contracts were awarded in previous years to investigate Hall thruster performance characteristics at $\mathrm{I}_{\mathrm{sp}}$ 's greater than 3000 seconds. The first supplier was the Boeing Corporation, which through subcontract to TsNIIMASH delivered the D-80 anode layer thruster [40]. The Atlantic Research Corporation supplied the second thruster, through subcontract to Fakel. This device was a magnetic layer thruster designated the SPT-1 [39]. The third supplier was the Busek Co., which built the BHT-HD-1000, also a magnetic layer thruster [41]. The thrusters have been operated at maximum voltages of $1700 \mathrm{~V}, 1250 \mathrm{~V}$, and $1000 \mathrm{~V}$ for the D-80, SPT-1 and BHT-HD-1000, respectively. The D-80 demonstrated an Isp range of 1600 to 4100 seconds, the SPT- 1 a range of 1600 to 3700 seconds and the BHT-HD-1000 a range of 1600 to 3300 seconds. Each thruster exhibited a range of voltages where the anode efficiency was maximized. This voltage was between 500 to $800 \mathrm{~V}$ depending on the mass flow rate. Precise evidence for this peak efficiency was not identified, but it was likely attributable to either increased electron current due to insufficient magnetic trapping or increased production of multiply-charged species due to the high voltages.

Building on these efforts, the objectives for NASA PY2002 and beyond are to: 1) identify the physical mechanisms that result in maximum efficiency with voltage, and 2) develop the design tools necessary to extend efficient operation in excess of the $800 \mathrm{~V}$ ceiling recently observed. To achieve these goals, internal GRC efforts are underway as well as investigations through a grant with the University of Michigan $[38,42]$ and through an NRA with MIT and Busek [43].

In conjunction with the University of Michigan, a $5 \mathrm{~kW}$ high voltage thruster designated the NASA-173M V.1 has been constructed and is shown in Figure 5. Initial testing has concentrated on characterizing the performance and identifying design variables most likely to increase efficiency. A follow on thruster designed entirely at GRC, the NASA-173MV.2, is currently in fabrication and scheduled for testing in Fall 2002.

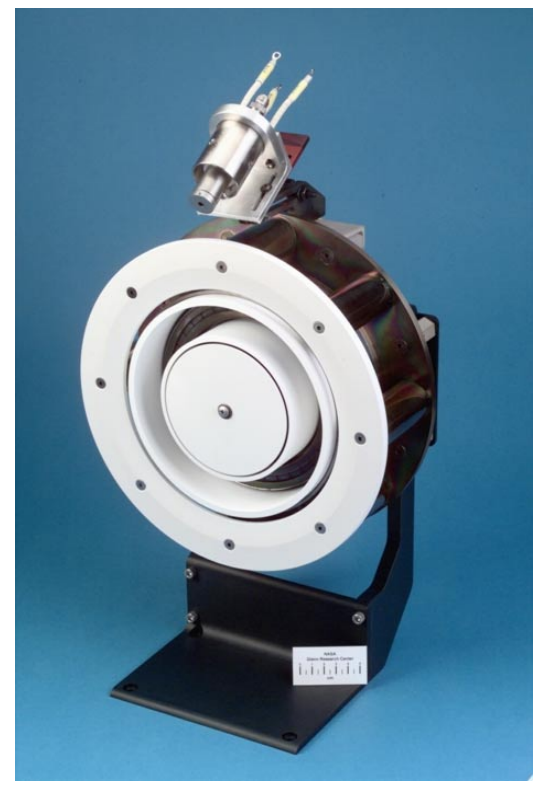

Figure 5 - The NASA-173M V.1. 
Recent results from the NASA-173M V.1 operating at 300 to $1000 \mathrm{~V}$ and $5 \mathrm{mg} / \mathrm{s}$ are shown in Figure 6 [38]. The figure shows two sets of data, with and without a trim coil energized. When there is no trim coil, only the inner and outer coils are used (the traditional design), the previously observed peak efficiency is found. With the trim coil energized, the efficiency is maintained at $>50 \%$ above $600 \mathrm{~V}$, demonstrating that efficient Hall thruster operation is possible at high voltage when the magnetic field is tailored for the operating point. Similar investigations at higher flow rates, and correspondingly higher efficiencies, are planned for the NASA-173M V.2 in coming months.

Work beyond PY2002 will focus on characterizing the plasma parameters of the NASA-173M thrusters using several diagnostics to assess what effects changes in the thruster are having on performance. These diagnostics will include the use of ion current density probes, and energy diagnostics such as ExB probes or ion energy analyzers. Internal plasma diagnostics using a high-speed probe system at the University of Michigan are also planned.

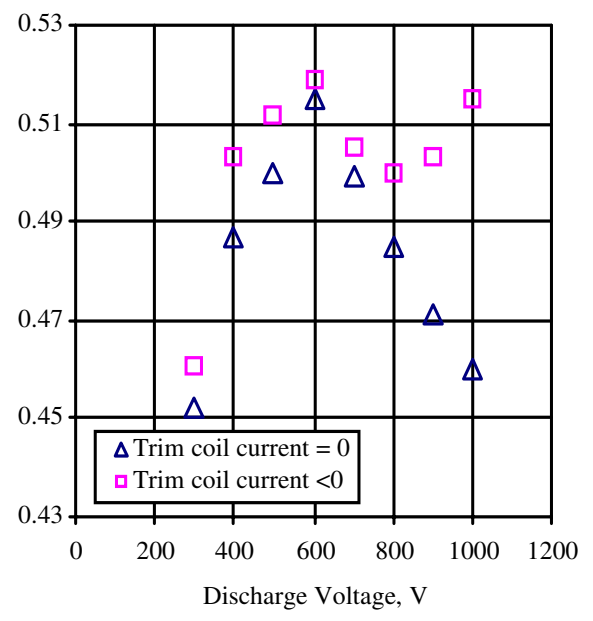

Figure 6 - Efficiency versus voltage for the NASA 173M V.1 operating at $5 \mathrm{mg} / \mathrm{s}$.

\section{High Voltage Thruster Life}

In 1999, NASA GRC began investigating Hall thrusters with specific impulses greater than the 1500 to 1700 seconds of SOA thrusters [39-42,44]. This increase in specific impulse over conventional xenon Hall thrusters was achieved by increasing discharge voltages from $300 \mathrm{~V}$ to as much as $1700 \mathrm{~V}$. Operation at these elevated discharge voltages substantially increased the kinetic energy of the ions produced during thruster operation. At any discharge voltage, some small fraction of the ions accelerated by the thruster impinge upon the thruster itself, eroding critical components, eventually causing the thruster to wear out. While experiments have shown this in the laboratory at voltages of 300 to $500 \mathrm{~V}$, the effect of discharge voltages in excess of $500 \mathrm{~V}$ on thruster lifetime has not been investigated.

The objective of the current investigation was to evaluate the effect of high voltage operation on thruster erosion. Specifically, a D-80 anode layer thruster was operated at $700 \mathrm{~V}$ and $4 \mathrm{~A}$. A $700 \mathrm{~V}$ discharge voltage was selected because a previous performance investigation demonstrated maximum efficiency at voltages between 500 to $800 \mathrm{~V}$ [40]. A 4 A discharge current was selected for extended operation because this was the maximum value that could be achieved while maintaining the desired steady state thermal conditions. The anode efficiency and specific impulse at this operating point were $57 \%$ and 2625 seconds, respectively. While efficiency over $70 \%$ and specific impulse over 4000 seconds were demonstrated at higher discharge voltages and currents, high thruster temperature prohibited operation for extended periods of time. The thruster was operated for a total duration of 1200 hours in this investigation. Erosion of critical thruster components was evaluated every 300 hours. The thruster exhibited asymmetric erosion that exposed the magnetic poles between the 600 and 900 hour increment (Figure 7). Even as the magnetic poles were exposed the robustness of the thruster was demonstrated by the continued nominal operation of the thruster. Jacobson [45] has a complete description of the thruster and test results.

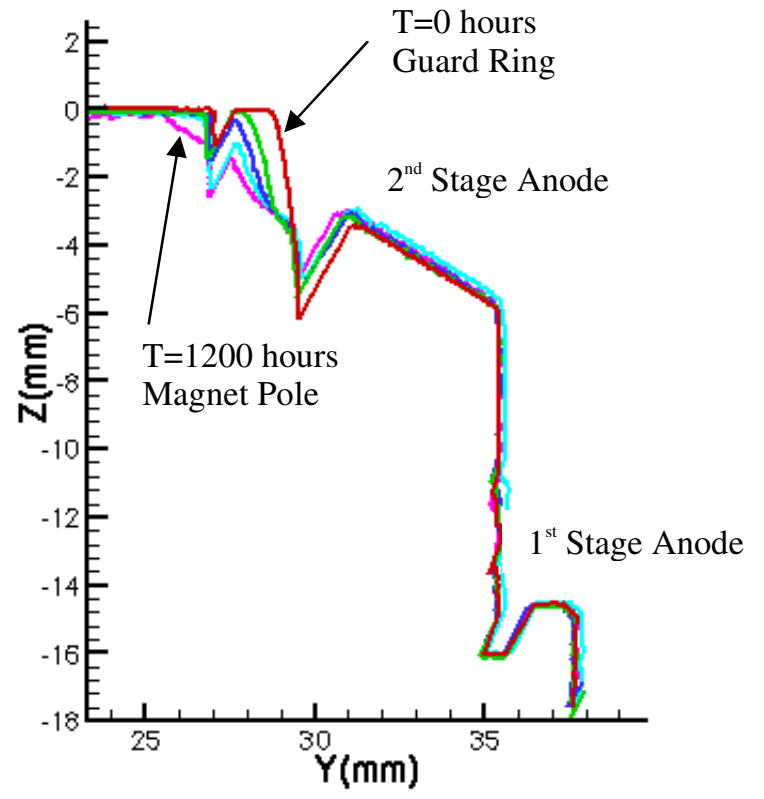

Figure 7 - D-80 Hall Thruster High Voltage Erosion CrossSections.

\section{SUMMARY}

NASA's Glenn Research Center has been selected to lead development of NASA's Evolutionary Xenon Thruster system, as follow-on to the highly-successful Deep-Space 1 system. The system is envisioned to incorporate a lightweight $40-\mathrm{cm}$ diameter electric propulsion thruster, a lightweight, modular power processing unit, a lightweight, low-volume, highly flexible advanced xenon feed system, and a simple, lightweight gimbal. During this two-phase program, the thruster will be developed to prototype model, with manufacturing of this unit conducted by General Dynamics Space Propulsion Systems. General Dynamics will also manufacture the AXFS. Boeing Electron Dynamic Devices will manufacture the PPU.

To date, fabrication of laboratory model $40 \mathrm{~cm}$ engines has been completed at GRC, and detailed performance 
characterizations are on-going at NASA. An engineering model 40-cm engine design has been assembled at GRC and is also under test. Typical engine performance at $6.9 \mathrm{~kW}$ is 4060 seconds specific impulse, $238 \mathrm{mN}$ thrust, and $69 \%$ efficiency.

The NASA Hall thruster program currently supports tasks for a number of customers including the Energetics Program, the Space Solar Power Program, and the In-space Propulsion Program. In program year 2002 the following was accomplished as part of these tasks: 1) A laboratory Hall thruster was built and tested to $72 \mathrm{~kW}$ and $3 \mathrm{~N}$ of thrust; 2) A $5.5 \%$ increase in thruster efficiency at high voltage was demonstrated by modifying the magnetic field profile; 3) High voltage Hall thruster lifetime was quantified; 4) A $96.5 \%$ efficient breadboard power module was demonstrated; 5) A technique for measuring the impedance of a Hall thruster was demonstrated; and 6) A plan for investigating the dynamic electrical behavior of Hall thrusters was presented.

\section{REFERENCES}

[1] Polk, J.E., et al., 1999, "Validation of the NSTAR Ion Propulsion System On the Deep Space One Mission: Overview and Initial Results," AIAA Paper No. 99-2274.

[2] Gershman, R., Manager, Planetary Advanced Missions, JPL, June 18, 1999, "ESS Technology Requirements."

[3] Anon., May 2001, Integrated In-Space Transportation Planning, Summary of Process and Technology Prioritization.

[4] Oleson, S.R., 2000, “Advanced Hall Electric Propulsion for Future In-Space Transportation," $3^{\text {rd }}$ International Conference on Spacecraft Propulsion, Cannes, France.

[5] Gefert, L.P. and Hack, K.J., 1999, "Options for the Human Exploration of Mars Using Solar Electric Propulsion," AIP Conference Proceedings, No. 458, STAIF-99.

[6] Leifer, S. and Noca, M., 1998, "Negative C3 Launch for Solar System Exploration,” AIAA Paper No. 98-3925.

[7] NASA's Office of Space Science, 2002 ROSS NRA, "InSpace Propulsion Technologies," Announcement.

[8] Patterson, M.J., et al., 2001, "Ion Propulsion Development Activities at the NASA Glenn Research Center," IEPC Paper No. 01-088.

[9] Patterson, M.J., et al., 2001, "Next-Generation 5/10 kW Ion Propulsion Development Status,” IEPC Paper No. 01-089.

[10] Soulas, G.C., 2001, "Design and Performance of $40 \mathrm{~cm}$ Ion Optics,” IEPC Paper No. 01-090.

[11] Sarver-Verhey, T.R., Domonkos, M.T., and Patterson, M.J., 2000, "Thermal Characterization of a NASA 30-cm Ion Thruster Operated up to 5 kW," AIAA Paper No. 2000-3816.
[12] Patterson, M.J., et al., 2000, "Ion Propulsion Development Activities at NASA Glenn Research Center," AIAA Paper No. 2000-3810.

[13] Rawlin, V.K., et al., 2002, "High Specific Impulse, High Power Ion Engine Operation,” AIAA Paper No. 2002-3838.

[14] Patterson, M.J., et al., 2002, "NEXT: NASA's Evolutionary Xenon Thruster,” AIAA Paper No. 2002-3832.

[15] Sovey, J.S., 1984, "Improved Ion Containment Using a Ring-Cusp Ion Thruster," Journal of Spacecraft and Rockets, Vol. 21, pp. 488-495.

[16] Pawlik, E.K. and Reader, P.D., 1967, “Accelerator Grid Durability Tests of Mercury Electron-Bombardment Ion Thrusters," NASA Technical Note D-4054.

[17] Patterson, M.J. and Sarver-Verhey, T.R., 1990, "5-kW Xenon Ion Thruster Lifetest,” AIAA Paper No. 90-2543.

[18] Patterson, M.J., et al., 1995, “2.3 kW Ion Thruster Wear Test," AIAA Paper No. 95-2516.

[19] Patterson, M.J., et al., 2001, "Recent Development Activities in Hollow Cathode Technology," IEPC Paper No. 01-270.

[20] Carpenter, C. and Patterson, M.J., 2001, "High-Current Hollow Cathode Development," IEPC Paper No. 01-274.

[21] Soulas, G.C., 2001, "Improving the Total Impulse Capability of Ion Thrusters With Thick-Accelerator-Grid Ion Optics," IEPC Paper No. 01-081.

[22] Soulas, G.C., 2001, "Performance Evaluation of Titanium Ion Optics,” IEPC Paper No. 01-092.

[23] Haag, T.W., et al., 2001, "Carbon Based Ion Optics Development at NASA GRC,” IEPC Paper No. 01-094.

[24] Kovaleski, S.D., et al., 2001, "A Review of Testing for the International Space Station Plasma Contactors," IEPC Paper No. 01-271.

[25] Kovaleski, S.D., 2001, "Life Model of Hollow Cathodes Using Barium Calcium Aluminate Impregnated Tungsten Inserts," IEPC Paper No. 01-276.

[26] Foster, J.E. and Patterson, M.J., 2000, "Enhanced Discharge Performance in a Ring Cusp Plasma Source," NASA/TM-2000-209765.

[27] Menart, J.A. and Patterson, M.J., 1998, "Magnetic Circuit for Enhanced Discharge Chamber Performance of a Small Ion Thruster," AIAA Paper No. 98-3343. 
[28] Patterson, M.J. and Grisnik, S.P., 1997, “Scaling of Ion Thrusters to Low Power," IEPC Paper No. 97-098.

[29] Pinero, L.P. and Bowers, G.E., 2001, "Sub-Kilowatt Power Processing Unit with an 8-cm Ion Thruster," IEPC Paper No. 01-331.

[30] Mantenieks, M.A., et al., 2001, "Low Energy Xenon Ion Sputtering Yield Measurements," IEPC Paper No. 01-309.

[31] Friedly, V.J. and Wilbur, P.J., 1992, "High Current Hollow Cathode Phenomena," Journal of Propulsion and Power, Vol. 8, No. 3, pp. 635-643.

[32] Kameyama, I. and Wilbur, P.J., 2000, "Measurements of Ions from High-Current Hollow Cathodes Using Electrostatic Energy Analyzer," Journal of Propulsion and Power, Vol. 16, No. 3, pp. 529-535.

[33] Williams, G.J., et al., 2000, "FMT-2 Discharge Cathode Erosion Rate Measurements via Laser Induced Fluorescence," AIAA Paper No. 2000-3663.

[34] Crofton, M.W., 2000, "The Feasibility of Hollow Cathode Ion Thrusters: A Preliminary Characterization," AIAA Paper No. 2000-5354.

[35] Kameyama, I. and Wilbur, P.J., 1998, "Potential-Hill Model of High-Energy Ion Production near High-Current Hollow Cathodes," International Symposium on Space Technology and Science Paper No. 1998-a-2-17.

[36] Manzella, D., Jankovsky, R., and Hofer, R., 2002, "Laboratory Model 50-kW Hall Thruster," AIAA Paper No. 2002-3676.

[37] King, D.Q., de Grys, K.H., and Jankovsky, R., 2001, "Multi-Mode Hall Thruster Development," AIAA Paper No. 2001-3778

[38] Hofer, R.R. and Gallimore, A.D., 2002, "The Role of Magnetic Field Topography in Improving the Performance of a High Voltage Hall Thruster,” AIAA Paper No. 2002-4111.

[39] Manzella, D.H., Jacobson, D.T., and Jankovsky, R.S., 2001, "High Voltage SPT Performance," AIAA Paper No. 2001-3774

[40] Jacobson, D.T., Jankovsky, R.S., Rawlin, V.K., and Manzella, D.H., 2001, "High Voltage TAL Performance," AIAA Paper No. 2001-3777.

[41] Pote, B. and Tedrake, R., 2001, "Performance of a High Specific Impulse Hall Thruster,” IEPC Paper No. 01-035.

[42] Hofer, R.R., Peterson, P.Y., and Gallimore, A.D., 2001, "A High Specific Impulse Two-Stage Hall Thruster with Plasma Lens Focusing,” IEPC Paper No. 01-036.
[43] Blateau, V., Martinez-Sanchez, M., Batishchev, O., and Szabo, J., 2001, "PIC Simulation of High Specific Impulse Hall Effect Thruster," IEPC Paper No. 01-037.

[44] Jankovsky, R.S., et al., 2001, “NASA's Hall Thruster Program,” AIAA Paper No. 2001-3888.

[45] Jacobson, D.J., 2002, "High Voltage TAL Erosion Characterization," AIAA Paper No. 2002-4257. 
Public reporting burden for this collection of information is estimated to average 1 hour per response, including the time for reviewing instructions, searching existing data sources, gathering and maintaining the data needed, and completing and reviewing the collection of information. Send comments regarding this burden estimate or any other aspect of this collection of information, including suggestions for reducing this burden, to Washington Headquarters Services, Directorate for Information Operations and Reports, 1215 Jefferson Davis Highway, Suite 1204, Arlington, VA 22202-4302, and to the Office of Management and Budget, Paperwork Reduction Project (0704-0188), Washington, DC 20503.

\begin{tabular}{|l|l|l}
\hline 1. AGENCY USE ONLY (Leave blank) & $\begin{array}{c}\text { 2. REPORT DATE } \\
\text { October } 2002\end{array}$ & $\begin{array}{r}\text { 3. REPORT TYPE AND DATES COVERED } \\
\text { Technical Memorandum }\end{array}$ \\
\hline
\end{tabular}

\section{TITLE AND SUBTITLE}

5. FUNDING NUMBERS

Ion Engine and Hall Thruster Development at the NASA Glenn Research Center

6. AUTHOR(S)

WU-755-B4-04-00

Matthew T. Domonkos, Michael J. Patterson, and Robert S. Jankovsky

7. PERFORMING ORGANIZATION NAME(S) AND ADDRESS(ES)

National Aeronautics and Space Administration

John H. Glenn Research Center at Lewis Field

Cleveland, Ohio 44135-3191

8. PERFORMING ORGANIZATION

REPORT NUMBER

E-13612

9. SPONSORING/MONITORING AGENCY NAME(S) AND ADDRESS(ES)

National Aeronautics and Space Administration

Washington, DC 20546-0001

10. SPONSORING/MONITORING

AGENCY REPORT NUMBER

NASA TM-2002-211969

IMECE-2002-34444

11. SUPPLEMENTARY NOTES

Prepared for the 2002 International Mechanical Engineering Congress sponsored by the American Society of Mechanical Engineers, New Orleans, Louisiana, November 17-22, 2002. Responsible person, Matthew T. Domonkos, organization code 5430, 216-433-2164.

12a. DISTRIBUTION/AVAILABILITY STATEMENT

12b. DISTRIBUTION CODE

Unclassified - Unlimited

Subject Categories: 20 and 75

Distribution: Nonstandard

Available electronically at http://gltrs.grc.nasa.gov

This publication is available from the NASA Center for AeroSpace Information, 301-621-0390.

13. ABSTRACT (Maximum 200 words)

NASA's Glenn Research Center has been selected to lead development of NASA's Evolutionary Xenon Thruster (NEXT) system. The central feature of the NEXT system is an electric propulsion thruster (EPT) that inherits the knowledge gained through the NSTAR thruster that successfully propelled Deep Space 1 to asteroid Braille and comet Borrelly, while significantly increasing the thruster power level and making improvements in performance parameters associated with NSTAR. The EPT concept under development has a $40 \mathrm{~cm}$ beam diameter, twice the effective area of the Deep-Space 1 thruster, while maintaining a relatively-small volume. It incorporates mechanical features and operating conditions to maximize the design heritage established by the flight NSTAR $30 \mathrm{~cm}$ engine, while incorporating new technology where warranted to extend the power and throughput capability. The NASA Hall thruster program currently supports a number of tasks related to high power thruster development for a number of customers including the Energetics Program (formerly called the Space-based Program), the Space Solar Power Program, and the In-space Propulsion Program. In program year 2002, two tasks were central to the NASA Hall thruster program: 1. The development of a laboratory Hall thruster capable of providing high thrust at high power; and 2. Investigations into operation of Hall thrusters at high specific impulse. In addition to these two primary thruster development activities, there are a number of other on-going activities supported by the NASA Hall thruster program. These additional activities are related to issues such as thruster lifetime and spacecraft integration.

14. SUBJECT TERMS

15. NUMBER OF PAGES

Ion thruster; Hall thruster 16

\begin{tabular}{|c|c|c|}
\hline $\begin{array}{c}\text { 17. SECURITY CLASSIFICATION } \\
\text { OF REPORT } \\
\text { Unclassified }\end{array}$ & $\begin{array}{c}\text { 18. SECURITY CLASSIFICATION } \\
\text { OF THIS PAGE } \\
\text { Unclassified }\end{array}$ & $\begin{array}{c}\text { 19. SECURITY CLASSIFICATION } \\
\text { OF ABSTRACT } \\
\text { Unclassified }\end{array}$ \\
\hline
\end{tabular}

NSN 7540-01-280-5500

Standard Form 298 (Rev. 2-89)

Prescribed by ANSI Std. Z39-18 298-102 